\title{
Factors that influence the use of birth control by Brazilian adolescents
}

\author{
Diogo Fajardo Nunes Hildebrand ${ }^{\prime}$ \\ Baruch College, City University of New York \\ Andres Rodriguez Veloso ${ }^{\Omega}$ \\ Universidade de São Paulo
}

\begin{abstract}
The central objective of this paper is to investigate the antecedents of the use of contraceptive methods by adolescents. For this purpose, we developed and tested a theoretical model that reflects the interrelationships between assessments of self-efficacy of youths and the influences of the partner, socializing agents and adolescents' goals in life. The results indicate that the intention to use and actual use of contraceptive methods is directly affected by perceptions of self-efficacy, life goals related to stability and education, and the respondent's sex (boys intend to use birth control methods more than do girls). Also, the attitude of the partner in the relationship and contact with doctors are preponderant factors influencing the intention to use birth control methods. These results are relevant from the theoretical standpoint, by providing a better understanding of adolescents' behavior, and from a practical perspective, by facilitating the development of marketing strategies and public policies to increase the use of birth control measures among young people.
\end{abstract}

Keywords: Adolescents; consumer behavior; contraceptive methods; social marketing.

\footnotetext{
* Author for correspondence:

${ }^{\dagger}$. Doctoral Student as Baruch College,

${ }^{\Omega} \mathrm{PhD}$ from the School of Economics,

City University of New York

Affiliation: Baruch College, City

University of New York

Address: 55 Lexington Ave.,New York

- NY - USA, 10010

Administration and Accounting of the

University of São Paulo

Affiliation: University of São Paulo

Address: Rua Luciano Gualberto, 908, São

Paulo - SP - Brazil

E-mail:

E-mail: veloso@usp.br

diogo.hildebrand@baruch.cuny.edu

Telephone: $(+1$ ) 646-709-6537

Telephone: (11) 3091-5879
}

Note from the Editor: This article was accepted by Bruno Funchal. 


\section{INTRODUCTION}

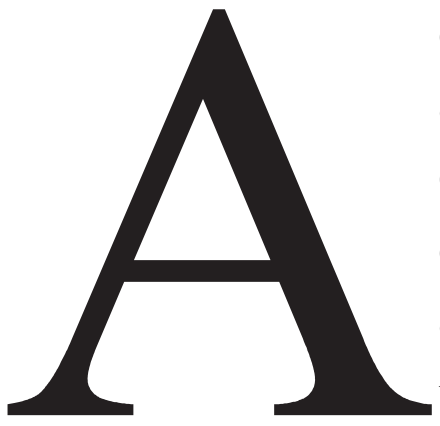

dolescence is the life phase when humans explore their biological and social limits. It is a period of change and transition between childhood and adulthood. Because it is a period of discoveries, doubts and uncertainties, there is a strong tendency for adolescents to engage in experimentation, making them vulnerable to risky activities that can have negative consequences in the short and long run (Irwin \& Millstein, 1986). The marketing area started to dedicate strong attention and efforts to study questions such as these in the 1970s (Kotler \& Zaltman, 1971; Kotler \& Lee, 2011). Since then, great efforts have been made to understand, from a marketing perspective, how it is possible to promote social causes, ideas or behaviors.

Adolescence can be defined and understood in different ways: as a sociocultural step that starts with rites of initiation and ends with the arrival of the adult phase, according to the prevailing social norms (anthropology); as a period after childhood and before reaching majority age, according to applicable legislation (law); as a step in life determined according to each society (sociology); or also a period of growth and development of the human being that starts with puberty and ends after two decades of life (medicine). According to the World Health Organization, the concepts of puberty, adolescence and youthhood are different. While the first involves a set of organic changes, adolescence covers the period of biopsychosocial transition between childhood and adulthood (chronologically running between the ages of 10 and 20 years), and youthhood encompasses the intermediate and final moments of adolescence and the first of maturity, between the ages of 15 and 25 years. Here we use a definition more tied to the anthropological view, that adolescence is a formative period particularly rich in destabilizing possibilities, a moment of various definitions in the sexual, professional and family areas and of sensitivity to outside influences. Regardless of the definition, adolescence is a phase of important physical, psychological and social transformations.

Studies in the United States indicate growth in the proportion of sexually active adolescents (Kalmuss et al., 2003), the same as occurs in Brazil (UNESCO, 2006). In a survey carried out in 2000 among @s in Brazil, UNESCO (2006) estimated that the average age of first sexual relations among Brazilians is between 13 and 14 years for boys and 15 and 16 years for girls. That study also indicated that in the country's main cities, $10 \%$ of boys 
between the ages of 10 and 14 years had already had sexual relations, impairing their psychosocial development.

Corroborating the alarming numbers indicated by UNESCO, UNICEF (2002) found that $32.8 \%$ of respondents to a survey between the ages of 12 and 17 years reported having engaged in sexual relations. Leite, Rodrigues \& Fonseca (2004) argue that even though Brazil's birth rate declined markedly in the twentieth century, the share of adolescent mothers has been increasing drastically. Furthermore, according to UNICEF (2002), among sexually active adolescents, 14\% have never used any birth control method and 32\% only do so infrequently. Finally, in the setting of a developed country, Kirby, Lepore \& Ryan (2005) found that roughly half of American youths have had at least one sexual relation.

A pregnancy during adolescence can not only cause a series of worries regarding the mother's and child's health, such as high rates of maternal morbimortality and higher risks of miscarriage and delivery complications (Leite, Rodrigues \& Fonseca, 2004), but mainly can bring socioeconomic problems to the family, such as interference in the mother's schoolingand the formation of fatherless and economically precarious families. All this impairs the psychological and social formation of the young mother as well as the child. Thus the theme of adolescent pregnancy is fundamental and analysis of the factors that prompt young people to use birth control measures is a necessity.

In 1999 in Brazil there were 705 thousand babies born to girls between the ages of 10 and 19 years (27\% of the total) in public hospitals (those associated with the National Health System, SUS), an increase of 67 thousand over the figure in 1993. Although there is no concrete information on the number of abortions (illegal in Brazil), the estimates are that the figure is around three times the number of births registered. According to the Ministry of Health, the main reasons for hospitalization of adolescent girls in Brazil are pregnancy complications, birth, postpartum problems and complications from abortions.

Academics from many areas of knowledge have thus been concerned with finding motivational, personal, biological and sociological variables that lead to the use of birth control measures (Boruchvitch, 1992; Romig \& Bakken, 1990; Kirby, Lepore \& Ryan, 2005) and in developing public policies to increase their use by adolescents (Avarett, Rees \& Argys, 2002; Grossman et al., 2006; Kalmuss et al., 2003). The focus of the most recent studies of the problem of teen and preteen pregnancy has evolved from simple birth control orientation to the need for a more comprehensive understanding of the characteristics of pregnant young 
girls and their partners. It is fundamental to know how these relationships arise, the values of the partners and their perspectives for self-realization, as well as the risks this type of relationship can cause. This knowledge appears essential to better understand what happens in these youths' lives and formulate ways to help them.

The present study unites previous findings and includes new factors, for the purpose of testing, from qualitative and quantitative perspectives, the antecedents that best explain the intention to use birth control methods among adolescents. Despite the growing attention paid to the theme, no published work has presented a conclusive study condensing the knowledge accumulated in a conceptual model. Therefore, we first present a review of the literature on sexual behavior and contraceptive use among adolescents and then make an exploratory effort to identify the relevant questions to measure the phenomena, and finally, by means of a conclusive study with the aid of the structural equation modeling technique, applied to human behavior, we map the antecedents of the use of contraceptives among adolescents.

\section{THEORETICAL FRAMEWORK AND RESEARCH HYPOTHESES}

In this section we explain the main concepts covered in this article and the hypotheses formulated based on the theoretical framework.

\subsection{Sexual Behavior Among Adolescents}

Before speaking about adolescents' use of contraceptives, it is first necessary to address the central matter of sexual behavior among @s. According to Kirby, Lepore \& Ryan (2005), sexuality in adolescence involves four main aspects: sexual initiation, frequency of sexual relations, use of contraceptives and number of partners.

The risk of pregnancy in the first months of sexual activity is high. Nearly one-third of patients get pregnant from their first partner (Abeche, 2002). The average period of sexual activity among adolescents before conception is six months. When considering only those who get pregnant from their first partner, this declines to three months (Morrison, 1985). Therefore, before entering the main part of the study - the use of contraceptives among adolescents - we analyze the reasons young adolescents start sexual activity early in life.

Since the interest in analyzing the sexual behavior of children aims to form public policies to resolve the problems inherent in adolescent pregnancy, the discussion of adolescents' sexual behavior needs to focus on the main demographic and personal factors that increase or decrease the probability of early start of sexual activity. Among the determining factors that should be mentioned, environmental and individual ones stand out. 
The social setting is known to be a key factor in the composition of peoples' character, determining their habits and socialization. Among the environmental factors that directly influence the decision on sexual life are the characteristics of the community, its organization, violence, hunger, etc. (Avarett, Rees \& Argys, 2002).

Studies indicate that characteristics of the family are important to determine the behavior of adolescents, particularly the stability of the parents' marriage, their educational level and the relations among family members (Kirby, Lepore \& Ryan, 2005), as well as their religion (Leite, Rodrigues \& Fonseca, 2004).

Friends also have a great influence on the decision on the start of sexual life, as does school performance or negative behaviors (Kirby, Lepore \& Ryan, 2005). Other studies demonstrate the importance of the partner and the intensity of the ties between the couple on the decision regarding sexual activity (Behrman, Kohler \& Watkins, 2002; Bühler \& Kohler, 2004).

Regarding schooling, studies in the United States and Brazil indicate that education is more important than household income in determining the sexual activity of youths, as well as other aspects of socialization (Kirby, Lepore \& Ryan, 2005; Leite, Rodrigues \& Fonseca, 2004).

An unfavorable environment can mold a deformed personality, confuse youths and not allow them to develop a proper notion of right and wrong. However, this influence is not correlated with the wealth of the environment, but rather with the social-emotional stability surrounding individuals during their formative years.

Besides the acknowledged environmental forces, there are countless individual characteristics that, when analyzing any population, clearly influence the decision of youths regarding sexual activity. First there are biological factors such as age, physical-hormonal development and gender. A wide range of studies concur that age and early puberty are strong influences for staring sexual activity, and that boys begin earlier than girls (Leite, Rodrigues \& Fonseca, 2004; Kirby, Lepore \& Ryan, 2005; UNESCO, 2006; UNICEF, 2002).

There are some divergences, however, regarding race or ethnicity. Studies in the United States suggest that non-Hispanic whites on average start their sexual life later than Afro-Americans, a correlation that declines when moderated by educational level. In contrast, studies in Brazil argue against this finding (UNICEF, 2002; Leite, Rodrigues \& Fonseca, 
2004), indicating only differences with no or little statistical significance among whites, mixed-race individuals and negroes, as well as only small statistical variations between people of Asian extraction and indigenous people (UNICEF, 2002), with the preponderant factors for the differences being other individual factors, such as schooling level (Leite, Rodrigues \& Fonseca, 2004).

Finally, mention must be made of psychological and cognitive traits, which are directly related to all behavioral characteristics, not just sexual activity. For example, positive self-esteem and self-concept have been indicated by many studies in the United States as influencing early sexual activity among boys and later activity among girls (Kirby, Lepore \& Ryan, 2005).

\subsection{The Use of Contraceptives Among Adolescents}

Considering the increasingly early start of sexual life and the complications in cases of early conception, the use of contraceptives among teenagers is of growing importance. However, between 12 and 15\% of sexually active adolescents in Brazil admit they do not use any birth control method (UNESCO, 2006), and 32\% only use them occasionally (UNICEF, 2002). In the United States, $70.2 \%$ of sexually active teenagers stated they used more than one type of contraceptive method in their most recent sexual relation (Averett, Rees \& Argys, 2002).

According to Dembo \& Lundell (1979), one of the factors associated with not using contraceptives among adolescents is the lack of knowledge about the sexual act. Darabi et al. (1982) corroborated this finding, indicating a lack of understanding among adolescents of menarchy, the menstrual cycle, time of fertility and the conception process. In a later study in Brazil among youths between the ages of 12 and 19 years, Martins et al. (2006) showed that with the high exposure of the population to information on birth control methods, $95 \%$ of the respondents said they knew about some type of contraceptive. However, when assessing the accuracy of these individuals on the use of these methods, the rate of correct answers was $70 \%$ for condoms, between $25 \%$ and $57 \%$ for the pill, and $50 \%$ for IUD and the rhythm method. In turn, Belo \& Silva (2004) found in a study among pregnant girls that only $32 \%$ of them used birth control methods before becoming pregnant and only $51.2 \%$ really wanted to get pregnant. Both studies suggest that although knowledge is high regarding birth control methods, this knowledge is often inaccurate, i.e., youths do not know enough to use the methods correctly. Of greater concern is the fact that despite the knowledge of contraceptives, 
a large portion of adolescents have not acquired the habit of using them systematically before engaging in sex.

These findings are thus reason for concern among public policymakers, who need to have a better idea of the intrinsic motivations of youths that cause them to use birth control methods. In the next topic we examine the main antecedents of the use of contraceptives among adolescents.

\subsection{Antecedents of the Use of Contraceptives Among Adolescents}

As is the case of works on the sexuality of young people, studies of the antecedents that influence the use of contraceptives are divided among various lines of investigation, including knowledge of human physiology and birth control methods (Dembo \& Lundell, 1979; Darabi et al., 1982; Leite, Rodrigues \& Fonseca, 2004), psychological/behavioral variables (Schor et al., 2002; Kirby, Lepore \& Ryan, 2005) and social/environmental factors (Boruchvitch, 1992; Ghimire \& Mohai, 2005; Avarett, Rees \& Argys, 2002; Grossman et al., 2006; Santiso-Galvez \& Bertrand, 2004). Here we use the variables that have shown greater relevance in earlier works to explain the intention to use and actual use of contraceptives among adolescents. More specifically, these antecedents derive from studies on self-efficacy, socializing agents, goals in life and sexual partner.

\subsubsection{Self-Efficacy}

Various theories address the theme of why people engage in risky behavior, among them the health belief model, the theory of reasoned action and social cognitive theory (Wulfert \& Wan, 1995). In a survey that assessed the intentions to practice safe sex among adults, Wulfert \& Wan (1995) used confirmatory factor analysis (CFA) to verify the adequacy of each model to evaluate the phenomenon. The results indicated that the first two models explained, respectively, $28 \%$ and $68 \%$ of the variance in the intention to use condoms, while the social cognitive model explained $79 \%$ of the variance (Wulfert \& Wan, 1995).

The social cognitive model used by Wulfert \& Wan (1995) was developed by Bandura in 1986, in which he proposed that humans' psychosocial development is not a monolithic process. Rather, human capabilities vary in their psychobiological origins and in the experimental conditions (Bandura, 1989).

According to Bandura (1998), in the main previously existing models to explain human behavior, behavior was modeled and controlled by only a causation model, containing 
environmental influences or internal dispositions. Social cognitive theory, according to Bandura (1989), favors a causation model involving triadic reciprocal determinism, according to which behavior, cognition and other personal factors and environmental influences all operate as interactive determinants that influence each other bidirectionally.

Because it satisfactorily explains preventive behavior in relation to sexual practices (Wulfert \& Wan, 1995) and due to its great utility as an instrument for social change and health promotion, we use the social cognitive model in this work to assess the use of birth control among adolescents, as well as indicate possible programs that can help reduce early pregnancy.

According to the theory of Bandura, protective behavior regarding health results from a process of cognitive evaluation by which the person integrates knowledge about a particular disease, the expected result associated with adoption of preventive behavior and social influences (Wulfert \& Wan, 1995). This integrative process results in a judgment of selfefficacy, which can be understood as an estimation of individuals' capacity to produce determined levels of performance that exercise influence over events that affect their lives (Bandura, 1994).

Further according to Bandura (1998), social cognitive theory involves sociostructural determinants of health along with personal determinants, which are fundamental operators on individuals' motivation and action in relation to preventive behavior. He stresses that an ample approach to promotion of health requires changes in the practices of social systems instead of simply changing individuals' habits, and that only the efforts that promote joint changes in the determinants of individual behavior, altering self-efficacy, can promote social change (Bandura, 1998).

Self-efficacy is defined by Bandura (1997, p. 3) as "belief in one's capacity to organize and execute the courses of action required to produce given attainments." In the case of the use of contraceptives among youths, self-efficacy is formed from two fundamental variables: the person's knowledge about the efficacy of the methods and his or her personality.

The theme of knowledge of human physiology and the use of birth control methods is widely discussed in communities, especially when the question is sex education of youths (Leite, Rodrigues \& Fonseca, 2004). As mentioned in the previous topic, despite the great dissemination of the subject of "sexuality" in society from a range of communication sources, 
the lack of quality in the teaching of this information, as well as the lack of interest among young people, impairs accurate knowledge of contraceptive methods (Martins et al, 2006). This shortage of accurate knowledge causes people to believe the use of contraception is incompatible with the frequency of sexual practice and that it interferes in sexual pleasure. Likewise, some still believe that they cannot get pregnant during adolescence (Morrison, 1985). The conclusion is that the knowledge accumulated about themes related to the sex act and birth control methods is a basic antecedent to determine contraceptive use among adolescents.

Besides knowledge about contraceptive methods, studies indicate that cognitive characteristics and personality traits have a great influence on the contraceptive behavior of young people. Adolescents with more advanced cognitive development have greater propensity to use a birth control method if they engage in sexual activity (Kirby, Lepore \& Ryan, 2005). Kirby, Lepore \& Ryan (2005) and Boruchvitch (1992) pointed out that youths with a greater locus of internal control use contraceptive methods with greater frequency. Elkind (1967) mentioned that with the development of egocentrism, adolescents have difficulty in perceiving they are vulnerable to risky events, as is also the case among adults. In complement to the study of Elkind (1967), Hern (1991) showed that sexually active young women have a tendency to overestimate the risk of other people getting pregnant in relation to their own chances.

Boruchvitch (1992) added to the discussion by reporting that studies of adolescent personality show that people with less ego maturity, greater difficulty of forming intimate relationships, inability to plan for the future, greater impulsiveness and low tolerance for frustration are less likely to use protective measures during sex.

Regarding factors related to personality, high self-esteem and positive self-concept, although they are factors inhibiting assumption of sexual risk during the initial phases of adolescence, they can increase risk-taking in subsequent phases (Kirby, Lepore \& Ryan, 2005).

Takiuti (1999) found a marked imbalance between the professed knowledge of adolescents about contraceptive methods and the real use of these methods. As in other areas, this finding reveals a duality or ambiguity with respect to questions of sexuality.

Therefore, besides knowledge about contraceptive methods, self-efficacy is formed by a set of personality traits that cause young people to assess with maturity, self-esteem and 
wisdom the importance of using birth control as well as the dosage or manipulation of contraceptives. In this form, our first hypothesis is:

$\mathrm{H}_{1}$ : Adolescents' self-efficacy positively influences their intention to use and use of birth control methods.

\subsubsection{Social/Environmental Variables}

There are a large number of social and environmental variables, and while individually they may not have great influence on behavior, when added to the other variables mentioned previously they directly impact the contraceptive behavior of adolescents. These factors have been investigated in a great range of settings, all the way from the force of Guatemaltec antiimperialist movements to the availability of family planning services to teenagers in the United States.

Studies of the high fecundity rate among adolescents in Guatemala attracted the attention of Santiso-Galvez \& Bertrand (2004), who in a comparative historical analysis showed the joint influence of the race of the population (predominantly indigenous), the civil war and socialist anti-imperialist movements and the close alliance of the government and the Catholic Church in the dissemination of family planning in communities. These findings demonstrate how the environment, by molding beliefs and cultural values, affects the population's behavior and reactions to public policies on population control.

Among the reasons indicated for the high birth rate among the women studied, the leading one was the dogmatic stance of the Catholic Church against contraceptive use because of the belief that sex must be solely for procreation. Therefore, the Catholic Church is an impediment to acceptance of family planning in more religious communities, causing a drastic reduction in the use of contraception (Santiso-Galvez \& Bertrand, 2004). Religious beliefs are thus an important antecedent of the decision to use contraceptives.

Despite the low correlation between household income and use of contraceptives (Leite, Rodrigues \& Fonseca, 2004), the average per capita income in the adolescent's community is negatively correlated with the probability of premature sexual activity (Leite, Rodrigues \& Fonseca, 2004; Averett, Rees \& Argys, 2002) and positively related with the use of contraceptives during adolescence (Averett, Rees \& Argys, 2002).

Recently the more macro approach has been supplemented with a more micro vision, in which social relationships among individuals are prioritized, because regardless of whether a person is white or black, Catholic or Protestant, or rich or poor, the factors that most BBR, Braz. Bus. Rev. (Engl. ed., Online), 
influence young peoples' behavior (in the case, the intention to use contraceptives) are the surrounding culture and way of acting and relating to other individuals. From this micro perspective, focusing more on personal relationships, Romig \& Bakken (1990) and Kirby, Lepore \& Ryan (2005) examined the impact of the family environment on children's behavior. The presence of caring and democratic parents who promote dialog with their children leads to a more aware attitude among youths, increasing their avoidance of risky behavior (Romig \& Bakken, 1990). Adding to the work of Romig \& Bakken (1990), Kirby, Lepore \& Ryan (2005), as well as Boruchvitch (1992), stressed the importance of family stability on the sexual and contraceptive behavior of children. Other important factors connected with the propensity for risk of youths are consumption of alcohol or illegal drugs and the moral values of parents (Kirby, Lepore \& Ryan, 2005).

As early as the 1960s, sociologists speculated that young people learn the basic "rational" aspects of consumption from their parents (Riesman, Glazer, \& Denny, 1956; Scott, 1959). Recent studies of socialization appear to support this premise. The family is a space of relationships and affective and moral identification (Coie et al., 1982) as well as a setting for relationships of authority and internal hierarchies. It is in this space of kinship and affective living that a feeling of subjectivity is modeled, associated with the first symbolic forms of social integration (Singly, 2000). Therefore, besides providing a solid and balanced structure, which the adolescent knows he or she can count on to face adversities, the family influences the young person's behavior by means of salutary communication and interrelation. These factors contribute to the use of contraceptive methods.

In turn, the interaction with peers influences the formation of a repertoire of responses for social adaptation. According to Silva (2001), it is from the relations with others that young people gradually build their self-concept, which will influence the way they deal with the different situations that life imposes. Thus, the perception of friends also is a preponderant factor for individual development, by contributing to build self-concept, because the success or failure perceived in social relationships impacts self-assessment, reinforcing - positively or negatively - determined behaviors. Since the perception of peers affects the social inclusion or exclusion of adolescents, the influence of friends on the formation of attitudes is strong (Coie et al., 1982). Besides this, youths tend to seek advice on various subjects from peers considered to be more experienced. The problem is that often this advice is not sufficiently reasoned and can provide spurious information, especially regarding taboo subjects involving 
sexuality and drug consumption, for instance. On the other hand, the initiative of young people to seek information from peers is laudable, because it indicates an attempt to increase knowledge on the theme. But this should be complemented by other sources of information. Due to the lack of empirical evidence on the subject, here we assume a positive effect of the interaction with peers on the use of contraceptives, although the contrary can be found.

The school, as a place that imparts knowledge and nurtures social relationships among adolescents, teachers and other staff, also supposedly has a positive influence on the consumption of contraceptives by youths. Besides school, it is logical to expect the adolescent's doctor (be it a gynecologist, pediatrician, urologist, general practitioner or other) influences the intention to use and the use of birth control methods.

Finally, mass culture plays a role, by circulating information and entertainment along with values and standards of conduct. Social subjects orient their practices and actions, reflect on reality and build and experiment with attitudes and habits based on parameters other than exclusively local ones, present in the school, family and immediate social circle. Therefore, individual and collective trajectories are not defined and developed only from experiences that are close in time and space. On the contrary, subjects are affected by models and references produced in physically distant and dispersed contexts. Studies of the influence of television have used the theory of cultivation (Gerbner et al., 2002 [not listed in references]). This theory consists of two main premises: that the world of television differs significantly from reality (greater wealth, more crime) and that this distortion influences the beliefs of spectators (they think that abundance and crime are common). Based on these premises, it is assumed that exposure to publicity campaigns that urge the use of birth control methods positively influences their use. On the other hand, the contrary can also logically happen, because watching programs such as soap operas that contain sex scenes, in which the couple do not use any birth control method, much less discuss it (as is the norm), can work against the use of contraceptives. Based on these reflections, we assume that:

$\mathrm{H}_{2}$ : Parents, friends, schools, doctors and the media have a net positive impact on the intention to use and use of birth control methods among adolescents.

\subsubsection{The Sexual Partner}

The majority of studies only consider the opinion of the girl regarding the relationship, without directly studying the partner. There is very little information for Brazil on the characteristics of the partner of adolescent girls who get pregnant and how the relationship 
was established and maintained (or not). Paiva, Caldas \& Cunha (1996) interviewed 100 adolescent mothers. According to the respondents, the age of the father ranged from 14 to 38 years (average of 19). The father reacted positively to the pregnancy in $75 \%$ of the cases, and the pregnancy was intentional in $42 \%$ of the cases, while the mother dropped out of school in $68 \%$ of the cases.

Many adolescents have idealistic and unrealistic beliefs about the probable consequences of a pregnancy, paternity and maternity. This has an important relationship with the etiology of pregnancy during adolescence. A survey using a questionnaire given to 1,546 Australian adolescents revealed that one-third of them had idealized beliefs, overestimating positive aspects and underestimating negative ones (Condon, Donovan \& Corkindale, 2001). The boys had greater levels of idealization.

Among American teenagers 13 to 18 years old, a significant association was observed between positive pregnancy feelings and perceived partner desire for pregnancy, limited future expectations and lack of school engagement (Hellerstedt et al., 2001).

The exploratory phase of the in-depth interviews with the adolescents in the present study revealed a strong tendency of youths to consider the sex act as something not planned. The adolescents preferred not to plan having sex. An explanation for this is that perhaps in some way this makes the person feel less "guilty" for having committed an act still considered to run counter to social mores. This lack of planning leads to lack of preparation and less discussion with the partner regarding the use of birth control. In such a situation, youths consider the subject of contraceptives as perturbing the ritual leading to the sex act, causing lower utilization. Therefore, the decision on whether or not to use a birth control method is commonly taken only minutes before the sex act and the opinion of the partner (the boy or the girl) is fundamental for the use or not.

Besides this, some youths of both sexes believe there is a greater chance of establishing a lasting relationship if a child is born (Abeche, 2002), clearly leading to lower usage of contraceptive methods. The above considerations lead to our third hypothesis:

$\mathrm{H}_{3}$ : The opinion of the partner regarding contraceptive methods has an impact on the intention to use and use of birth control methods among adolescents.

\subsubsection{Goals in Life And Personal Realization}


The lack of response to programs to prevent adolescent pregnancy is cause for reflection on the complexity of the problem. A study involving interviews with 135 new adolescent mothers at Hospital de Clínicas in the city of Porto Alegre in 1991 and 1992 found that $41.5 \%$ of the respondents reported the pregnancy had been planned (Cericatto et al., 1994). Many may find it hard to understand how young girls, often in their early teens, can want a pregnancy. But for girls with limited horizons for realization in school or the job market and with expectations of changes in their lives due to pregnancy, it can represent a moment of raised self-esteem and of self-realization (Franco, Rodrigues \& Dionísio, 1998). Therefore, it is not surprising that campaigns with a limited vision of the problem, relating it to a lack of proper orientation, can have unimpressive results. Based on this, we formulated our fourth and last hypothesis:

$\mathrm{H}_{4}$ : Youths with greater goals for professional and financial realization will have higher intention to use and use of birth control methods.

Based on the theoretical framework discussed above, the figure below summarizes the influences on the use of birth control methods among adolescents and the hypotheses developed.



$\mathrm{H} 4$

Figure 1: Theoretical model to understand the antecedents of the use of birth control methods

\section{Method}

This section discusses the methodological aspects of the study and describes the procedures used in formulating the survey design, collection of data, definition of the sample, analytic techniques and testing of the hypotheses.

\subsection{Procedures for Sampling and Data Collection}

The study was carried out in three steps. The first consisted of in-depth interviews with the aim of investigating the perceptions of youths about the research problem, solidifying the hypotheses and identifying places that could be used for the quantitative step. In the 
second step, based on a pre-test, we made some alterations to the survey design and data collection instrument. The third step was to carry out the cross-sectional survey with the objective of testing the hypotheses established.

Due to the incipient stage of research on the use of birth control in Brazil and the need to develop a valid and reliable research instrument, we carried out an exploratory phase to formulate relevant questions on sexuality among adolescents. This helped the researchers better understand the nuances involving the process of using contraceptive methods as well as refine the variables to be included in the quantitative phase and the attributes best suited to measure them. We conducted 16 in-depth interviews (8 with gynecologists and 8 with adolescents), using a script to elicit responses on important aspects of adolescent sexuality. From the information generated in this first step, along with the literature review, we prepared a structured questionnaire.

For the quantitative step, we used a sample of 344 adolescent students from two schools in the city of Porto Alegre: 166 from a public school and 178 from a private one. This number is in line with the recommendation of Anderson \& Gerbing (1988), that a sample should have at least 150 respondents for analysis by structural equations. Before administering the questionnaire, we contacted the school principals and teachers to obtain permission to give the questionnaire, answered anonymously in writing, to the students during class time. This procedure had the main advantage of surveying the adolescents in a situation where each could respond to the questions without interference from classmates. In addition, we believed there would be good willingness to answer the questionnaire because of the freedom to interrupt the studies temporarily. For the process to be as random as possible, we scheduled varied days and times, in the morning and afternoon.

Before distributing the questionnaires, the researcher read the following instructions: “This survey is part of a study developed in a master's degree program in marketing. Before answering, please read each question carefully. Please sit apart from each other and answer without looking at the questionnaires of your classmates. Thank you." Afterward, the researcher asked all of them if they agreed to participate, and then the questionnaires were handed out.

The presence of the researcher during application of the questionnaire was necessary because in general adolescents are not used to responding this type of academic research, especially involving a culturally charged theme like sexual behavior. In this respect, the 
presence of the researcher to clarify any doubts was important to avoid joking that would divert the respondents' attention.

The data from the questionnaires were entered by the researcher in an electronic file using the SPSS 13.0 software. During this process, the questionnaires were inspected visually to identify those where the respondents had not answered all the questions or had not filled in the form correctly (e.g., not marked the answers on the scale). All questionnaires with problems were disregarded.

\subsection{Preparation of the Data}

Before analyzing the data, we carried out a preparation step. According to Tabachnick \& Fidell (2001), this is essential to assure the validity of the assumptions of the analyses and hence of the results. We analyzed the missing values, extreme cases (outliers), normality and homoscedasticity of the data.

The analysis of the missing values was done visually rather than by using the routine in the SPSS software package because the researcher, in typing in the data, verified there were almost no unanswered items and no pattern was identified, allowing the inference that the instances of unanswered items were random (MCAR - missing completely at random) (Tabachnick \& Fidell, 2001). Only two questionnaires contained two items with omitted values. The missing values were replaced with the sample mean of the respective variables.

Next we analyzed the univariate and multivariate outliers. No univariate outlier located more than three standard deviations from the mean was found. The greatest distance in individual cases was in the question regarding the degree of self-confidence in relation to choosing which brands to consider when buyng condoms[Brands of condoms? The title in Portuguese indicates the study involved condom usage, but all the text indicates the interest is in birth control methods in general, so I took the liberty of generalizing the title. This sudden mention of brands, in the context of all the preceding discussion, is very jarring, "out of left field" as the saying goes.], but no significant outlier was identified regarding this or other variables. The analysis of multivariate outliers was done by calculating the Mahalanobis distance. In this respect, Tabachnick \& Fidell (2001) and Hair et al. (1998) recommend using a conservative level of significance $(\mathrm{p}<0.001)$ to exclude multivariate outliers. We only identified and excluded one.

The analysis of normality revealed that none of the variables were outside the accepted standards of normality. Both indices were in the ranges recommended by Kline (1998), with 
kurtosis above 8 and skew greater than 3. The homoscedasticity - also called homogeneity of variances when one of the variables is nominal - was measured by the Box Test, generated by SPSS for the MANOVA conducted, which "tests the null hypothesis that the observed covariance matrices of the dependent variables are equal across groups" (SPSS, 2003). A nonsignificant F-statistic indicated there were no differences in the covariance matrices across the groups, giving support to the assumption of homogeneity. The results of the Box Tests are presented together with the results of the analyses.

\subsection{Operationalization of the Variables}

The matters discussed here involve the development of the questionnaire, which was guided by the main objective of this study, to test the hypotheses formulated. Nevertheless, another aim was to obtain additional information on the sexual experience of young people. Therefore, we divided the questionnaire into three parts. The first contained items concerning the scales applied, the second had questions about aspects of the sexual experiences of the respondent and the third questions to obtain demographic data and information on attitudes toward use of birth control.

The questions were almost the same for the two subsamples investigated, students from public and private schools. Only a few adaptations were made to make the questions more understandable to the public school students. The questions covered a range of aspects investigated by other authors: Bandura (1997) - self-efficacy (7 items); Franco, Rodrigues \& Dionísio (1998) - life goals (3 items); Paiva, Caldas \& Cunha (1996) - influence of the partner on the use of a contraceptive method (3 items); Kirby, Lepore \& Ryan (2005) influence of socializing agents ( 7 items) and intention to use birth control methods (3 items); and Santiso-Galvez \& Bertrand (2004) - perception of approval of society on the use of contraceptives and adolescent pregnancy. The questions taken from American studies were translated to Portuguese and checked for accuracy by the reverse translation technique and then validated for content through analysis by two professors of marketing, both doctoral candidates in the graduate program in marketing of Rio Grande do Sul Federal University (UFRGS).

\subsection{Statistical Analysis}


Several statistical methods were employed to investigate the data. These included calculation of basic descriptive statistics, univariate tests and multivariate analyses involving structural equation modeling. The descriptive statistics, including the mean, standard deviation and other indicators, were computed to obtain a "general impression" of the data, and principally to examine the demographic variables and data on sexual attitudes toward contraceptives.

The SPSS 13.0 program was used to calculate the descriptive statistics and apply the tests of the difference of means and to run the multiple linear regression, while EQS 5.6 and AMOS 4 were applied to the structural equation modeling (SEM). SEM is a multivariate technique that combines aspects of multiple regression (examining relations of dependence) and factor analysis. This approach offers various benefits, among them permitting the use of a more complex structure that can include latent variables (variables not measured directly) and observable variables (indicators of latent variables). It also enables simultaneous analysis of a group of relationships (Hair et al., 1998).

\subsubsection{Criteria for Application of the Structural Equation Modeling}

The expression "structural equation modeling" communicates two important aspects of this approach: that the causal processes studied are represented by a series of structural equations and these structural relationships can be modeled pictorially, providing a clear visualization of the theory of interest. In this respect, the hypothesized model can be tested statistically in a simultaneous analysis of the entire system of variables, to determine the extent to which it is consistent with the data (Byrne, 1994).

Some criteria serve as a basis for suitable use to the SEM. One of them is the need for a consistent and comprehensive theoretical foundation guiding the model to be tested. The most common mistake indicated by Klyne (1998) in application of the SEM is that of specifying the model after collection of the data. This is because this practice limits the analysis to the variables collected, omitting other important ones and ignoring the fact that the SEM does not serve to explore hypotheses, but rather to confirm them; In other words, SEM should be guided much more by a theoretical perspective than by empirical results (Hair et al., 1998). In this respect, we believe the theoretical framework presented meets this criterion, because it was developed based on conceptual and empirical studies that examined the constructs included here and that establish sufficiently solid mutual associations. Kline (1998) stresses that this is not a limitation of the SEM. Rather, it is a characteristic that favors 
sustained theoretical development. He adds that the use of the SPSS software and multiple regression analysis before the modeling is strongly recommended to provide more empirical support to the researcher, although this does not exclude the need for theory in the model to be tested.

In relation to the sample, two characteristics are important for SEM: size and selection process. The sample size for arbitrary, non-normally distributed data should be in a ratio of 10:1 of respondents per parameter (Bentler \& Chou, 1988). Hair et al. (1998) recommend a sample of 200 cases. For use of SEM in experimental studies, a larger sample size is recommended, because the more groups formed by the factors, the larger the necessary sample will be (Bagozzi, 1977), and the fact this method is not often used in experimental studies requires a larger margin for error. In the present study there are no specification errors and the model has 24 parameters (i.e., measurement model + structural model). Therefore, our sample of 344 respondents, even with indications of a non-normal data distribution, can be considered adequate in terms of size.

The sample selection process can face many obstacles that are hard to overcome and the use of a probabilistic sample of this population can be very difficult, if not impossible. In the present study, there is a shortage of reliable information on the sexually active adolescent population. Therefore, we used a non-randomized sample, which does not rule out the use of the SEM. Nevertheless, while the results obtained can be generalized for a population similar to that in the sample, they cannot be extended to the population at large.

\subsubsection{Criteria for Fitting the Structural Equation Model}

Since the variables (self-confidence, attitude toward complaints and probability of success) are constructs, and as such are complex and abstract, their measurement is by means of scales with multiple indicators. Their validity and reliability must be assessed before their use in the analyses. The testing of the model's fit to the data is done by analyzing goodnessof-fit indices. We accomplished this by using confirmatory factor analysis (CFA), carried out with the AMOS software applying the maximum likelihood estimation method (MLE). This method is by far the most common in marketing studies. According to Pampel (2000), MLE maximizes the probability that the observed variables are representative of the population, that is, this method estimates the best chance of reproducing the observed data, and unless the researcher has strong reasons otherwise (e.g., very large sample), this method should be used. 
To assess the fit of the FCA model, we used the indicators listed in Table 1. These are divided into three groups: absolute measures of fit - which determine to what degree the general model predicts the covariance matrix or the observed correlation; comparative measures - which compare the proposed model to the null model; parsimony measures which provide the base for comparisons between models of different complexities and objectives (Hair et al., 1998). The absolute measures of fit are $\chi^{2}$ (chi-squared), which measures the significance of the differences between the observed and estimated matrix for the model presented (Hair et al., 1998); root mean square residual (RMSR), which indicates the mean of the residuals adjusted between the estimated and observed matrices; and root mean square error of approximation (RMSEA), which represents the discrepancy between the observed and estimated matrices, taking into consideration the degrees of freedom attained. The compared measures of fit are the comparative fit index (CFI) and the normed fit index (NFI), which are comparative indicators between the estimated and null model (Hair et al., 1998); and the non-normed fit index (NNFI), which combines a measure of parsimony in a comparative index between the proposed and null models.

Table 1: Indices and Criteria for Evaluation of the Model Fit (CFA)

\begin{tabular}{ll}
\hline Indices & Evaluation Criteria \\
\hline \hline Chi-Squared / Degrees of Freedom & Values between 1 and 5 \\
CFI (Comparative Fit Index) & Greater than or equal to 0.9 \\
NFI (Normed Fit Index) & Greater than or equal to 0.9 \\
NNFI (Non-Normed Fit Index) & Greater than or equal to 0.9 \\
RMSR (Root Mean Square Residual) & The smaller the better \\
RMSEA (Root Mean Square Error of Approximation) & Between 0.05 and 0.08 \\
\hline
\end{tabular}

The purpose of the confirmatory factor analysis was to verify the validity of the constructs by ascertaining their one-dimensionality, reliability, convergent validity and discriminant validity. The one-dimensionality was evaluated by analysis of the standardized residuals, following the recommendations of Garver \& Mentzer (1999). To assess the reliability of the scale, we adopted the internal consistency method, which evaluates the homogeneity of the set of items. Thus, we calculated Chronbach's alpha, which is one of the most used procedures to assess the reliability of a scale (Malhotra, 2001). We also checked the reliability of the extracted variance, from the sum of the standardized loadings and the measurement errors of the indicators because, according to Bagozzi (1994), the Cronbach's alpha coefficient becomes inflated when the scale has a large number of items. 
The convergent validity, attained when the indicators that measure the phenomenon are correlated (Evrard, Pras \& Roux, 1993), was verified by examining the significance of the standardized loading factor statistic for each of the two manifest variables, based on the respective t-values (Bagozzi, 1994). The convergent validity is considered to be acceptable when each of the standardized factor loadings presents a t-value greater than or equal to 1.96 . The discriminant validity, in contrast to the convergent validity, involves the extent to which the scale is not correlated with measures of other constructs from which it is supposedly distinguished (Churchill, 1995). To assess the discriminant validity, we performed a procedure consisting of comparison between the variance extracted from the dimension and its shared variances (the square of the correlation coefficient) with the other dimensions (Fornell \& Larcker, 1981). The discriminant validity is positive when all the dimensions present extracted variances greater than the respective shared variances.

After establishing the validity and reliability of the constructs that compose the proposed model, we performed simultaneous evaluation of the dimensions to observe the extent to which the measurement variables were strongly correlated with their respective latent constructs, and not related with the other dimensions from which they are assumed to be distinguished (Churchill, 1995). When integrated, starting from the simultaneously analyzed dimensions, the model becomes more complex, which according to Bagozzi (1994), tends to reduce the indices of fit, so that the conventional threshold values can be interpreted more strictly.

We considered the possibility of re-specifications and removal of parameters with the aim of improving the fit of this measure by the multivariate Lagrange multiplier (LM) test, which indicates those that can be suppressed in the model. The SEM encompasses two distinct sub-models: the measurement model, which demonstrates the relationship between constructs and their indicators, and the structural model, which specifies the relationships between the constructs. The recommendations in the literature are first to establish the validity and reliability of the measures used before testing the structural model (Anderson \& Gerbing, 1988; Kline, 1998). This is known as the two-step approach.

\subsubsection{Two-Step Approach}

Next we used the two-step approach used by Santos (2001). Anderson \& Gerbing, cited in Santos (2001), recommend this approach for causal models, in which the measurement model is confirmed and then the structural model is tested. The measurement 
model includes all the indicators used to measure the constructs, and its investigation offers an assessment of the convergent and discriminant validity of the set of metrics utilized. Only after examining the measurement model are the relationships between the constructs and the nomological validity of the structural model verified.

We tested the relationships of the constructs using the hybrid structural equation model, which establishes the relationships between the theoretical constructs that are part of the proposed structural model. One of the main advantages of this approach, which unites the measurement model and the structural model, is precisely the possibility of considering in the statistical analysis the measurement errors of the variables included in the theoretical model, in contrast to analyses considered "traditional", which do not include the measurement errors in the statistical evaluations (Kline, 1998).

In the hybrid model proposed, the independent latent variables are self-efficacy, influence of socializing agents, life goals of the adolescent and influence of the sex partner. The other independent variables are the school (public or private) and the respondent's sex (codified as dummy variables in both cases).

\section{RESULTS}

In this section we first present the results of the in-depth interviews and the characterization of the sample used in the descriptive study, by means of the demographic data collected. Then we carry out a univariate descriptive analysis of the variables examined. Finally, we explore the results of the multivariate analyses, involving the measurement model and structure model.

\subsection{In-Depth Interviews}

In this preliminary step we conducted 16 in-depth interviews to increase our familiarity with the study objective and the concepts involved. The main purpose was to gain a better understanding of adolescent sexuality and its different mechanisms of development, and more specifically, to improve the application of the variables and the operationalization of the constructs in the theoretical framework.

We sought to understand how the perception of adolescents about their peers, parents, the media and society as a whole influences the use of contraceptive methods. This was an important element for investigation, because we were in doubt about the inclusion of another construct (influence of socializing agents) in the theoretical structure. The youths interviewed stated they first seek and evaluate information from their peers. However, most of them 
recognized that this source is limited, making it necessary to look for other sources. They also expressed full awareness that the media does not favor the use of birth control methods. An emblematic comment in this respect was: "Besides these campaigns at carnival time for us to engage in safe sex, in the soap operas and that kind of show you never see a couple waiting for the man to put on a rubber." This common depiction of sexual encounters on television shows appears to reinforce the notion that contraceptive methods impair romance and the spontaneity of sex. There was huge heterogeneity regarding the level of interaction and communication with parents about sexual issues. In some cases talking about sex with parents was seen as a presage to the end of the world, while in other cases the youths stated they felt totally at ease seeking advice on sexual matters from their parents.

We diagnosed that sexuality is in general a taboo subject for the adolescents and hence that the questionnaire should be carefully formulated so as not to inhibit the respondents from revealing their perceptions about sex. The reason is that society still discourages sexual activity among youths. Behind the outward erotic freedom that marks modern society there is still a sense of shame and an ideal that adolescents should remain chaste (Damatta, 1991). "I don't feel comfortable talking about this with anybody, especially my parents," was one comment. In another interview, a teenage boy asked repeatedly "You're not going to talk about this with anyone, are you?"

The interviews with the physicians (general practitioners and gynecologists) revealed the social problem that teenage pregnancy represents, because the specialists (mainly those involved in assistance work) reported that pregnancy among adolescents is very common in lower income areas. One of the respondents made it clear that "among those with better financial conditions, abortion is more common than imagined." The doctors also stressed that having clear goals for personal realization is a key factor discouraging early pregnancy. One of the specialists commented that "we need to see the problem with open eyes and without preconceptions: a young girl without clear goals in life won't be likely to use contraceptive measures, because for her pregnancy is a boon in life."

\subsection{Quantitative Study}

Based on the results of the exploratory phase, we began the quantitative phase of the study, in which the hypotheses in the model were tested. 


\subsubsection{Characterization of the Sample}

The sample was almost equally divided between boys and girls (51\% to $49 \%)$. The average age was 16 years (s.d. $=1.08)$ and $34 \%$ of the respondents came from families with monthly income greater than six thousand reais $(\mathrm{R} \$ 6,000)$, while the household income was less than $\mathrm{R} \$ 2,000$ in $25 \%$ of the cases.

The majority of the respondents stated they had never engaged in sex (53.5\%), while $25.5 \%$ had done so one or more times with a single partner and $21 \%$ had had more than one partner. Among those reporting sexual activity, 59\% used at least one contraceptive method. This means that $41 \%$ of the adolescents in the sample who had engaged in sex placed themselves in a situation of risk of pregnancy or contracting a sexually transmitted disease (STD. Among the 166 public school students surveyed, the risk exposure was much greater, because of the $62 \%$ who reported engaging in sex in this subsample, $46.6 \%$ did so without any contraceptive at least once. These results reveal the urgent need for effective sex education before youths reach the age where they are likely to become sexually active.

The descriptive results also show that $54 \%$ of the respondents had never spoken to a physician regarding contraception and that $29 \%$ had spoken to a doctor about the matter only one time. These figures are an alert to the medical community that they need to find alternatives to convey information to adolescents regarding birth control measures. Regarding interaction with parents, only $49 \%$ of the respondents stated they spoke to their parents about contraceptive methods. On the other hand, 61\% stated they converse with friends. This supports the results of the qualitative phase, in which peers emerged as the primary source of information about birth control methods.

With respect to life goals, $72 \%$ of the youths said they intend to attend college and $87.5 \%$ intend to establish a good financial situation before thinking about having kids. This indicates a high level of maturity among the respondents and that most of them want to delay starting their own families. These results also reveal an incongruent situation, because while the majority were aware that it is best to wait to establish financial and structural stability before having children, a good part of the respondents had engaged in sex without using contraceptives, indicating a lack of accuracy in the evaluation of self-efficacy in adolescence, as indicated by Bandura (1989). However, the comparison of the means showed that among those intending to go to college and to establish financial stability before having a child, the intention to use contraceptives was significantly higher, validating the fourth hypothesis 
regarding the importance of life goals on propensity to use birth control methods. The significance test $(\mathrm{F}=145.723 ; \mathrm{p}<0.000)$ corroborated the marked difference in the average of the responses on the intention to use and use of contraceptives between the two groups.

\subsubsection{Discussion of the Measurement Model}

Based on the recommendations of various authors (Hair et al., 1998; Churchill, 1999), the validity of a model is basically supported if: (a) the measurement model fits the data reasonably well, that is, attains goodness-of-fit indices considered satisfactory; (b) the factor loadings of the indicators in the corresponding factors are large and significant; (c) indicators of a single construct produce reliability indices greater than 0.70 and extracted variance higher then 0.50 ; (d) the correlations between the indicators (or factors) of a single construct produce evidence of convergent validity; and (e) analysis of the correlations between constructs indicate discriminant validity (Santos \& Rossi, 2002).

Initially, to test the invariance of the measurement model in the two types of school public and private - we estimated the model simultaneously for each sample, by means of multigroup structural equation modeling. Following the procedures carried out by Sirdeshmukh et al. (2002), we first restricted the parameters as invariant in the two groups and estimated a totally restricted model. Then, based on the Lagrange-multiplier test (Byrne, 1994), we "released" the parameters with significant indicators up to the point when this release did not significantly improve the model. In this case, no parameter was indicated that, upon being released, improved the model fit, meaning that measurement model used can be considered adequate for the two groups of students. The indices of fit for the model were: $\chi^{2}=$ $1878.495, \mathrm{df}=721, \chi 2 / \mathrm{df}=2.60, \mathrm{NFI}=0.96, \mathrm{NNFI}=0.98, \mathrm{CFI}=0.97$ and $\mathrm{RMSEA}=0.06$, all of them indicating satisfactory fit.

Further regarding the measurement model, the convergent validity was basically supported by the fact that all the items presented high and significant factor coefficients for the constructs we proposed to measure (between 0.69 and 0,89, t-values greater than 9.47). Besides this, the items associated with a single construct showed significant mutual correlations. Therefore, there was convergence of the measures, that is, the existence was detected of a strong correlation of the metrics intended to measure each construct (Churchill, 1999).

Evidence of the discriminant validity was provided by the levels of pairwise correlation between the constructs. Correlations above 0.80 indicate lack of discriminant 
validity, that is, the constructs in question are measuring the same phenomenon. By this criterion, the constructs were distinct from each other, with the highest correlation being that between self-efficacy and life goals (0.51).

Finally, the measurements utilized supplied satisfactory levels of reliability and extracted variance. The reliability ranged from 0.79 to 0.90 (influence of socializing agents and influence of sex partner, respectively). The extracted variance was between 0.54 and 0.69 (self-efficacy and influence of the sex partner, respectively). This evidences the internal consistency among the multiple indicators of a variable, showing that they are really measuring a single construct and substantially explaining the respective latent constructs.

\subsubsection{Discussion of the structural model}

After examining the measures used, we then shifted our focus to the theoretical framework developed, which establishes relations among the theoretical constructs proposed. We first investigated the set of hypotheses by means of the goodness-of-fit indices of the hybrid model and the significance and magnitude of the estimated regression coefficients. As well, we calculated the coefficient of determination for each structural equation. This coefficient represents the proportion of the variance of the dependent variable that is explained by the independent variables.

Before caring over those analysis, however, we analyzed the multigroup structural equations to investigate if joining the data from the two types of schools (public and private) was appropriate or whether the models should be estimated separately. The biggest advantage of this procedure is to increase the precision of the parameters estimated. As for the measurement model, we used the Lagrange-multiplier test to gauge the need to allow the nomological relations established to vary according to the type of school. We did not detect any parameter that, upon being allowed to vary, significantly improved the model fit. Therefore, the data could be grouped in a single sample database.

The results of the structural model of the database with 344 respondents are shown in Table 2. The chi-square value is significant. However, because this test is very sensitive to the deviations from normality and to samples greater than 200 observations, the analysis of the chi-square value should be done in composition with other criteria of fit (Hair et al., 1998). Examination of the degrees of freedom produced a satisfactory value (1.60), well below the maximum recommended value (5). The CFI, NFI and NNFI were all above 0.90, considered very satisfactory, and the RMSEA of 0.05 was acceptable. 
The effect of the perceptions of self-efficacy on the intention to use and use of birth control methods, established in hypothesis $\mathrm{H}_{1}$, was supported by the results. However, among the significant effects, this was the lowest. The impact of the sex partner on the use of contraceptives was high (0.23), suggesting that the decision on such use is a process involving both partners in the relationship. The fact having the goal of establishing financial stability before having a child was also a determining factor of the use of birth control methods (0.17), as was the gender of the respondent (0.24), in which case boys expressed a greater intention to use them than did girls.

With respect to the impact of socializing agents on the intention to use birth control methods, the results indicate that parents, school and media have little influence on youths' decision. Only the recommendation of doctors and the level of contact with specialists were shown to exercise strong influence on this decision (0.26). Friends had a significant influence, but a weak one (0.09).

Table 2: Estimated coefficients of regression of the theoretical relations established in the model

\begin{tabular}{|c|c|c|}
\hline Relationships of the model & Standardized regression coefficient $t^{\mathrm{a}}$ & Hypothesis \\
\hline \multicolumn{3}{|c|}{ DEPENDENT VARIABLE: INTENTION TO USE AND USE OF CONTRACEPTIVE } \\
\hline \multicolumn{3}{|l|}{ METHODS } \\
\hline Self-efficacy & $0.11(2.04)$ & $\mathrm{H}_{1}$ - Confirmed \\
\hline Life goals & $0.17(3.14)$ & $\mathrm{H}_{4}$ - Confirmed \\
\hline Sex partner & $0.23(3.93)$ & $\mathrm{H}_{3}$ - Confirmed \\
\hline Gender & $\mathbf{0 . 2 4}(4.47)$ & \\
\hline Age & $0.05(0.81)$ & \\
\hline Influence of socializing agents & & $\mathrm{H}_{2}-$ Confirmed \\
\hline Parents & $0.02(0.41)$ & \\
\hline Friends & $0.09(1.70)$ & \\
\hline Media & $0.05(0.75)$ & \\
\hline School & $0.06(0.97)$ & \\
\hline \multirow[t]{2}{*}{ Doctors } & $0.26(2.56)$ & \\
\hline & $\mathbf{R}^{2}=\mathbf{0 . 3 1}$ & \\
\hline \multicolumn{3}{|l|}{ Goodness-of-fit indices: } \\
\hline 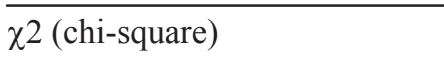 & $1056(\mathrm{p}<0.01)$ & \\
\hline DF (degrees of freedom) & 657 & \\
\hline CFI (comparative fit index) & 0.96 & \\
\hline NFI (normed fit index) & 0.94 & \\
\hline
\end{tabular}




\begin{tabular}{ll}
\hline \hline NNFI (non-normed fit index) & 0.96 \\
RMR (root mean sq. residual) & 0.27 \\
RMSEA (root mean sq. error of approx.) & 0.06 \\
\hline
\end{tabular}

${ }^{a} \mathrm{t}$-values between parentheses. Based on a single-tailed test: $\mathrm{t}$-values $>1.65=\mathrm{p}<0.05$; and $\mathrm{t}$-values $>2.33=$ $\mathrm{p}<0.01$. Significant coefficients in boldface (all at the 0.01 level).

Of particular interest to policymakers regarding programs to encourage contraceptive use is the relative influence of doctors and friends. While the results showed that doctors have a strong influence on the intention to use birth control methods, $54 \%$ of the respondents reported never having spoken to a physician about the subject, and a further $29 \%$ had only done so on one occasion. In contrast, friends have little influence but are the main source of information on contraceptives (the descriptive results show that $61 \%$ of the respondents reported asking friends for information).

\section{FINAL CONSIDERATIONS}

The aim of this work was to study the risk behavior of adolescents regarding contraception to avoid pregnancy. As indicated by the professionals interviewed and evidence in the literature, despite the media campaigns promoting the prevention of sexually transmitted diseases, little attention is given to adolescent pregnancy, which can bring negative biological, economic and social consequences for the mother and child. In this context, the public sector needs to develop more effective activities. The expanded use of social marketing can address this question by indicating ways that institutions such as the government can develop more adequate marketing activities. In the case studied here, the central objective would be to encourage the use of contraceptives. The considerations made below stress the information that can be utilized by those engaged in public health and public policies.

From an academic perspective, the structural model demonstrated the importance of self-efficacy, socializing agents, life goals and opinion of partners on the decision of youths to use birth control methods. Although the theme is still a social taboo, the risks run by youths and the findings presented here indicate the need for public policies to make educators, parents and adolescents more aware of the need for contraception from the first sexual experience.

Important socializing agents, such as the schools, media and parents, should be used to convey information on the risks and probability of conception at an early age. Because not all youths seek advice from physicians and other health care professionals before starting their 
sexual lives, but trust their recommendations, schools and parents need to do more to encourage youths to consult specialists and the media needs to step up efforts to provide information on the inherent risks of sexual activity and questions concerning contraception.

Socializing agents should reinforce the importance of life planning and completion of education, so that adolescents will form more responsible life goals. More than having access to contraceptives, adolescents need to be more aware of the problems of early pregnancy, because they often want this. Only a change of attitude by the government (which needs to increase the dissemination of information through the media), schools and the family, leaving aside taboos and accepting the reality that adolescents are starting their sexual lives at an ever younger age, can change this worrying situation.

Our objective here is not to condemn sex during adolescence, because experimentation in relations with others and sexual activity are fundamental for the biological, psychological and social development of young people. The problem occurs when this experimentation is not accompanied by the proper awareness or planning, and consequently without protection. As put by Professor Abeche of the UFRGS School of Medicine in one of the in-depth interviews: "Today in our society, everything is unfavorable (...). The media does not depict sexual protection as a necessity, the sex act is seen as something unplanned or morally disturbing. Childhood sexuality is exploited absurdly. Youths are not given the time they need to develop awareness and plan sex before experimenting with it."

With more of an explanatory and informative than prescriptive purpose, our aim here is to bring relevant information on a theme that can be considered a disease with strong potential to spread in such an alienated society. This work is an attempt to apply concepts of consumer behavior to study not only questions related to selling by companies, but to social questions, to contribute to the common welfare.

\subsection{Limitations and Suggestions for Future Research}

The contributions brought by this work must be considered in light of the limitations of this study. The cross-sectional approach and non-probabilistic sample, composed of adolescents at the schools studied at the moment of data collection, limit the generalization of the results. Although we investigated different school settings to test the stability of the model constructed, we suggest the application in other schools as well as in communities with lower life quality and where youths tend to drop out of school at an early age. 
Besides this, future studies could investigate other antecedents than those considered here, seeking to increase the predictability of these variables. Other suggestions for future work are studies over longer time horizons, to monitor the phenomenon and people involved over a longer period. Finally, the school origin of the youth (public or private) could be included as a moderating factor in the relations of the model.

\section{REFERENCES}

ABECHE, A. M. A gestante adolescente e seu parceiro: características do relacionamento do casal e aceitação da gravidez. 2002. 80 f. Dissertação (Mestrado em Medicina) - Programa de Pós Graduação em Medicina, Departamento de Clínica Médica, Faculdade de Medicina da Universidade Federal do Rio Grande do Sul, 2002.

ANDERSON, J. C.; GERBING, D. W. Strutural equation modeling in practice: a review and recommended two-step approach. Psychological Bulletin, Vol. 103, No. 3, p. 411-23, 1988.

AVARETT, S.; REES, D.; ARGYS, L. M. The impact of government policies and neighborhood characteristics on teenage sexual activity and contraceptive use. American Journal of Public Health, Vol. 92, No. 11, p. 1773-1778, 2002.

BAGOZZI, R. P. Structural equation models in experimental research. Journal of Marketing Research, Vol. 14, No 2, p. 209-226, 1977.

BAGOZZI, R. P. Structural equations models in marketing research: basic principles. In: Principles of marketing research. Cambridge: Blackwell, 1994. p. 317-385.

BANDURA, A. Exploration of fortouitous determinants of life paths. Psychological Inquiry, Vol. 9, No. 2, p. 95-99, 1998.

BANDURA, A. Self efficacy: the exercise of control. New York: Freeman, 1997.

BANDURA, A. Self-efficacy. In: RAMACHANDRAN, V. S. (Ed.). Encyclopedia of human behavior. New York: Academic Press, 1994. Vol. 4, p. 71-81.

BANDURA, A. Social cognitive theory. In: VASTA, R. (Ed.). Annals of child development: six theories of child development. Greenwich, CT: JAI Press, 1989. Vol. 6, p. 1-60.

BEHRMAN, J. R.; KOHLER, H-P.; WATKINS, S. C. Social networks and changes in contraceptive use over time. Demography, Vol. 39, No. 4, p. 713-738, 2002.

BELO, M. A. V.; SILVA, J. L. Conhecimento, atitude e prática sobre métodos anticoncepcionais entre adolescentes gestantes. Revista de Saúde Pública, Vol. 38, No. 4, p. 479-487, 2004.

BENTLER, P.; CHOU, C. Practical issues in structural modeling. In: LONG, S. J. (Ed.) Common problems-proper solutions: avoiding error in quantitative research. Beverly Hill: Sage, 1998. p. 161-192. 
BORUCHOVITCH, E. Fatores associados a não-utilização de anticoncepcionais na adolescência. Revista de Saúde Pública, Vol. 26, No. 6, p. 437-443, 1992.

BÜHLER, C.; KOHLER, H-P. Der einfluss starker beziehungen auf die nutzung moderner kontrazeptiva in Kenia. Zeitschrift, Vol. 33, No. 1, p. 5-25, 2004.

BYRNE, B. M. Structural equation modeling with EQS and EQS-windows: basic concepts, applications, and programming. Thousand Oaks: Sage, 1994.

CERICATTO, R. et al. Anticoncepcão e gravidez na adolescência: fatores associados.

Revista da Associação Médica do Rio Grande do Sul (AMRIGS), Vol. 38, No. 4, p. 294298, 1994.

CHURCHILL, G. Marketing research. Orlando: Fryden Press, 1999.

COIE, J.; DODGE, K.; COPPOTELLI, H. Dimensions and types of social status: a cross-age perspective. Developmental Psychology, Vol. 18, No. 4, p. 557-570, 1982.

CONDON, J. T; DONOVAN, J.; CORKINDALE, C. J. Australian adolescents' attitudes and beliefs concerning pregnancy, childbirth and parenthood: the development, psychometric testing and results of a new scale. Journal of Adolescence, Vol. 24, No. 6, p.729-742, 2001.

DAMATTA, R. A casa e a rua. Rio de Janeiro: Guanabara, 1991.

DARABI, K. F. et al. Evaluation of sex education outreach. Adolescence, Vol. 17, No. 65, p. 57-64, 1982.

DEMBO, M. H., LUNDELL, B. Factors affecting adolescent contraception practices: implications for sex education. Adolescence, Vol. 16, No. 56, p. 657-64, 1979.

ELKIND, D. Egocentrism in adolescence. Child Development, Vol. 38, No. 4, p. 1025-1034, 1967.

EVRARD, Y.; PRAS, B.; ROUX, E. Market: études et recherché en marketing. Paris: Nathan, 1993.

FORNELL, C.; LARCKER, D. Evaluating structural equation models with unobservable variables and measurement error. Journal of Marketing Research, Vol. 18, No. 18, p. 39-50, 1981.

FRANCO, J.; RODRIGUES, M. G.; DIONÍSIO, M. J. A adolescência e a gravidez: um estudo fenomenológico. Revista de Psiquiatria Consiliar e de Ligação, Vol. 4, No. 1, p. 3339, 1998.

GARVER, M. S.; MENTZER, J. T. Logistics research methods: employing structural equation modeling to test for construct validity. Journal of Business Logistics, Vol. 20, No. 1, p. 33-57, 1999.

GHIMIRE, D. J.; MOHAI, P. Environmentalism and contraceptive use: how people in less developed settings approach environmental issues. Population and Environment, Vol. 27 No. 1, p. 29-61, 2005. 
GONÇALVES, D. A. A influência dos pacotes de preço na decisão de consumo de serviços. 2005. 95 f. Dissertação (Mestrado em Administração) - Programa de PósGraduação em Administração, Universidade Federal do Rio Grande do Sul, Porto Alegre, 2005 .

GROSSMAN, D. et al. Barriers to contraceptive use in product labeling and practice guidelines. American Journal of Public Health. Vol. 96, No. 5, p. 791-799, 2006

HAIR, J. et al. Multivariate Data Analysis. New Jersey: Prentice Hall, 1998.

HELLERSTEDT, W. L. et al. Pregnancy feelings among adolescents awaiting pregnancy results. Public Health Reports, Vol. 116, suppl. 1, p. 180-193, 2001.

HERN, A. L. Perceptions of vulnerability to pregnancy and the use of effective contraception. Personality and Social Psychology Bulletin, Vol. 17, No. 1, p. 104-110, 1991.

IRWIN Jr., C.E.; MILLSTEIN, S.G. Biopsychosocial correlates of risk-taking behaviors during adolescence. Journal of Adolescence Health Care, Vol. 7, suppl. 6, p. 825-965, 1986.

KALMUSS, D. et al. Preventing sexual risk behaviors and pregnancy among teenagers: linking research and programs. Perspectives on Sexual and Reproductive Health, Vol. 35, N. 2, p. 87-93, 2003.

KIRBY, D.; LEPORE, G. Sexual risk and protective factors. The National Campaign to Prevent Teen and Unplanned Pregnancy, ETR Associates, 2005.

KLINE, R. Principles and practice of structural equation modeling. New York: The Guilford Press, 1998.

KOTLER, P.; LEE, N. Marketing social: influenciando o comportamento para o bem. Porto Alegre: Bookman, 2011.

KOTLER, P.; ZALTMAN, G. Social marketing: an approach to planned social change. Journal of Marketing, Vol. 35, No. 3, p. 3-12, 1971.

LEITE, I. C.; RODRIGUES, R. N.; FONSECA, M. C. Fatores associados com o comportamento sexual e reprodutivo entre adolescentes das regiões sudeste e nordeste do Brasil. Cadernos de Saúde Pública, Vol. 20, No. 2, p. 474-481, 2004.

MALHOTRA, N. K. Pesquisa de marketing: uma orientação aplicada. 3. ed. Porto Alegre: Bookman, 2001.

MARTINS, L. B. M. et al. Fatores associados ao uso de preservativo masculino e ao conhecimento sobre DST-AIDS em adolescentes de escolas públicas e privadas do município de São Paulo, Brasil. Cadernos de Saúde Pública, Vol. 22, No. 2, p. 315-323, 2006.

MORRISON, D. M. Adolescent contraceptive behaviour: a review. Psychological Bulletin, Vol. 98, No. 3, p. 538-568, 1985.

NAMEROW, P. B.; LAWTON, A. I.; PHILLIBER, S. G. Teenagers' perceived and actual probabilities of pregnancy. Adolescence, Vol. 22, No. 86, p. 475-85, 1987. 
PAIVA, A. S.; CALDAS, M. C.; CUNHA, A. A. Perfil psicossocial da gravidez na adolescência. In: MONTEIRO, D. L. M. Gravidez na adolescência. São Paulo: Revinter, 1998.

RIESMAN, D.; GLAZER, N., DENNY, R. The lonely crowd. New Hampshire: Yale University Press, 1956.

ROMIG, C. A.; BAKKEN, L. Teens at risk for pregnancy: the role of ego development and family processes. Journal of Adolescence, Vol. 13, No. 2, p. 195-199, 1990.

SANTISO-GALVEZ, R.; BERTRAND, J. T. The delayed contraceptive revolution in guatemala. Human Organization, Vol. 63, No. 1, p. 57-67, 2004.

SANTOS, C. P. dos. Impacto do Gerenciamento de Reclamações na confiança e lealdade do consumidor, no contexto de trocas de serviços relacionais. 2001. $253 \mathrm{f}$. Tese (Doutorado em Administração) - Programa de Pós-Graduação em Administração, Universidade Federal do Rio Grande do Sul, Porto Alegre, 2001.

SANTOS, C. P.; ROSSI, C. A. V. The impact of complaint handling on consumer's trust and loyalty in the context of relational services exchanges. In: EUROPEAN MARKETING ACADEMY CONFERENCE, 31., 2002, Braga. Proceedings... Braga: EMAC Conference, 2002.

SCHOR, N. et al. Adolescência: vida sexual e anticoncepção. In: ENCONTRO NACIONAL DE ESTUDOS POPULACIONAIS, 11., 2002, Caxambu. Anais... Caxambu: ABEP, 2002.

SCOTT,W. Empirical assessment values. American Sociological Review. Vol. 24, No. 3, p. 299-310, 1959.

SILVA, V. Indicadores de rejeição em grupo de crianças. Dissertação (Mestrado em Psicologia) - Pós-Graduação em Psicologia Clínica, Universidade Federal do Paraná. Curitiba, 2001.

SINGLY, F. O eu, o casal e a família. Lisboa: Dom Quixote, 2000.

TABACHNICK, B.; FIDELL L. Using multivariate statistics. Needham Heights: Allyn \& Bacon. 2001.

TAKIUTI, A. D. Contribuição ao estudo de um modelo de atendimento ao adolescente no sistema público de saúde. 1999. 189 f. Tese (Doutor em Medicina) - Programa de Pós Graduação em Medicina, Faculdade de Medicina da Universidade de São Paulo, 1999.

UNESCO. Pesquisa juventudes e sexualidade. 2006. Disponível em:

$<$ http://www.unesco.org/new/pt/brasilia/about-this-office/unesco-resources-in-brazil/studiesand-evaluations/violence/youth-and-sexuality/>. Acesso em: 12 out. 2006.

UNICEF. Pesquisa a voz dos adolescentes no Brasil. 2002. Disponível em: $<\underline{\text { http://www.vozdosadolescentes.org.br/ }>\text {. }}$ 
WULFERT, E.; WAN, C. K. Safer sex intentions and condom use viewed from a health belief, reasoned action, and social cognitive perspective. The Journal of Sex Research, Vol. 32, No. 4, p. 299-311, 1995. 